\title{
Setting the agenda for health in Europe
}

\section{What the United Kingdom could do with its presidency of the European Community}

Next week the United Kingdom takes over the presidency of the European Community for six months. The pace of change, the problems posed by fragmenting eastern European countries, and the controversy engendered by certain parts of the Maastricht treaty may preoccupy the presidency. This would be a pity.

Article 129 of the Maastricht treaty commits the European Community to a formal and direct interest in public health for the first time, which gives the United Kingdom a unique opportunity to use its presidency to provide a strategy and a new agenda for European health. This new mandate for the European Community has not had an easy gestation. Previously the community focused mainly on economic and trading matters, topics with implications for health being addressed indirectly through non-health programmes. In the early 1970s the commission began a programme concerned with standards of air and water; more recently health and safety at work have attracted attention. Two previous attempts to take public health into the main terms of reference have been frustrated by the European Commission, and attempts to include any aspects of national systems of medical care in the public health chapter of the treaty have met with widespread opposition.

In Maastricht last December agreement was finally reached on the boundaries of public health. ${ }^{1}$ Depending on your point of view, the community will now be able to take a substantial interest in public health ${ }^{2}$ or else this interest will be marginal and extremely limited. ${ }^{3}$ The greatest gain, however, may be symbolic: in the words of the health committee of the House of Commons, "the general shift in the Community role marked by the Maastricht treaty may represent a movement away from the purely economic and market orientated focus of the original community which might have considerable significance in the public health arena in the future." ${ }^{3}$ This could mark a useful first step in the process of taking seriously the threats to public health and the environment. ${ }^{45}$

The new article commits the community to working towards improving people's health by encouraging cooperation between states and funding it if necessary. The article specifically identifies prevention of diseases as part of its remit - in particular, "the major health scourges including drug dependence, by promoting research into their causes and their transmission, as well as health information and education." It emphasises the need for coordinating policy and programmes and cooperating with international organisations such as the World Health Organisation. The possibility of incentives to develop health policies is also made explicit. To the detached observer these terms of reference at least have potential; to the public health opportunist they seem positively exciting.

The exclusion of medical care from article 129 may well be a blessing in disguise (despite the wishes of those wanting a strong central directive to bring resources available to the British NHS into line with those of other member states). The level of funding and the necessary reorientation of health systems towards preventive medicine, primary health care, and community care are certainly priorities, but they are very much a matter for local political decisions - in keeping with the community's principle of subsidiarity. The issues of the wider public health are different: food production, alcohol and drug misuse, the control of HIV infection and other infectious diseases, and the protection of the environment transcend the sovereignty of any one country. The recent events in Croatia and Bosnia, to mention only two contemporary trouble spots, remind us of the fragility of social systems even within Europe and that equity and peace are prerequisites of health, as WHO recognised in its original charter. Health therefore needs to be represented in the community's committees; the question of whether there should be a separate public health directorate in Europe will not go away once this has happened.

What then are the tasks that should be carried out during the United Kingdom's presidency? Of primary importance is to clarify the use of the term "public health," which countries use differently. The Acheson Committee's definition of public health as "the science and art of preventing disease, prolonging life and promoting health through organised efforts of society" has much to commend it. ${ }^{6}$ If this definition was adopted in Europe it would pave the way for a systematic examination of the impact on health of many different policies. It could also lead to a genuine debate about a health strategy for Europe, with everybody-not just "experts"participating. An outbreak of democracy seems one of the likely outcomes of the Danish referendum on the Maastricht treaty.

Currently the list of topics for action in article 129 is something of a ragbag, including tobacco, the free movement of professionals and the mutual recognition of qualifications, the pharmaceutical industry, cancer, poisoning, nutrition, and research. An agenda for action might include the exchange of experience in and research on urban and environmental health; the development of healthy schools, hospitals, 
and workplaces; programmes of harm reduction for drug and alcohol misuse; the promotion of sexual health and the prevention of HIV infection and AIDS; and community based approaches to healthy nutrition and the prevention of heart disease. This would require recognising the relevance to health of agricultural policy and food production and marketing. A wealth of experience now exists on all these topics. ${ }^{7-9}$ The United Kingdom could provide a rational framework as valuable in its own way as The Health of the Nation promises to be.

A particular service that the president might perform would be to open up access to the European Community's funds for research. Too often it seems that cliques are able to obtain funding but outsiders cannot. Biomedical research has tended to dominate over epidemiological and social inquiry, which forms the basis of a public health strategy. The British government has tackled much of this at home and is in a strong position to address it in Europe.

A final point about the relationship between the European Community and WHO: WHO is in one of its perennial financial crises. The advent of a public health presence in Europe presents an opportunity to get to grips with an organisation that is still based on a 1948 command model. Our own health service reforms provide the guide here: a drastically slimmed down strategic head office could be linked to member states for policy and to institutions and field programmes for technical support. WHO need not supply this technical support directly: member states have vast skilled networks that could provide it better. WHO and the European Community together playing the role of enabler and catalyst must be the way forward. Unfortunately, some very strong vested interests exist, and secretaries of state are not usually in office for long enough to get to grips with the last of the big bureaucracies. This could be the time to startwith WHO in Europe acting in concert with a slim, strategic minded public health directorate of the community. A red herring that is currently being used to justify the continuation of the status quo is the public health crisis in eastern Europe; this poses a different set of questions, which should be tackled independently by the community.

In its conclusion to the third report on the European Community and health policy the British government's health committee stated, "We recommend that, in response to this report, the government seize the opportunity to lay out its agenda for health during its forthcoming presidency." Much of the groundwork has already been done at home. The United Kingdom's relationship with Europe has not often been a happy one. Yet our record and skill in public health is generally acknowledged to be outstanding: here we have a chance to make a really positive contribution to our neighbours. It would be a pity if we missed our chance.

I acknowledge the contributions of Carlos Alvarez Dardet (Valencia), Bo Petterson (Stockholm), Lowell Levin (New Haven), and Susanna Sans (Barcelona) to this editorial.

Head,

JOHN ASHTON

Department of Public Health,

University of Liverpool, Liverpool L69 3BX

1 Maastricht treaty on European union. CONE-UP, 1862, 1862/9

2 Ham C, Berman P. Health policy in Europe. BMF 1992;304:855-6.

3 House of Commons Health Committee. Third report: European Community and health policy. London HMSO, 1992.

4 Bruntland GH. Our common future: the report of the World Commission on Environment and Development. Oxford: Oxford University Press, 1987.

Ashton J. Sanitarian becomes ecologist: the new environmental health. BMf 1991;302:189-90. 6 Committee of Enquiry into the Future Development of the Public Health Function. Public health in England. London: HMSO, 1988. (Cmnd 289; Acheson report.)

Ashton J, Seymour J. The new public health. Milton Keynes: Open University Press, 1988.

8 Ashton J, ed. Healthy cities. Milton Keynes: Open University Press, 1992.

9 Vandra J. Valencia. International fournal of Health Promotion (in press).

\section{Selective serotonin reuptake inhibitors}

\section{A modest though welcome advance in the treatment of depression}

The selective serotonin reuptake inhibitors are a group of drugs that have been regarded as a major advance in the treatment of depression. Those recently marketed in Britain include fluvoxamine, fluoxetine, sertraline, and paroxetine. Their effectiveness has been shown in placebo controlled trials, ${ }^{1-4}$ while comparisons with other antidepressants have sometimes suggested greater efficacy or a more rapid effectand sometimes the opposite. ${ }^{5}$ Conflicting results should be expected; they may be due to methodological imperfections, such as selection bias or unsatisfactory matching, or they may occur by chance. A single trial rarely if ever justifies an unequivocal claim of superiority, and no selective serotonin reuptake inhibitor has been shown consistently to be therapeutically superior to other antidepressants.

Few placebo controlled trials of these drugs have been carried out in depressive disorders in elderly people, and claims for their effectiveness in these patients have been based on the results of comparisons with other antidepressants. Nor have placebo controlled trials been carried out in patients with truly "resistant depression" - a term used in different ways by different investigators. The results of a trial suggesting, for instance, a beneficial response to a selective serotonin reuptake inhibitor in those who have not responded to a relatively short course of a tricyclic antidepressant provides insufficient reason to believe that this group of drugs will benefit most patients with resistant depression. Continued treatment with them may help prevent relapse and recurrence of depression ${ }^{67}$-though again not to a greater extent than with tricyclic antidepressants.

Like other antidepressants, selective serotonin reuptake inhibitors are effective in anxiety (and panic) as well as depressive disorders. Anxiety and depression go hand in hand and may be difficult to distinguish from each other, especially in general practice. Doubt persists whether the benefit is due to treatment of any underlying depression or whether the drugs have specific anxiolytic or antipanic effects. ${ }^{8}$ Similar considerations apply in obsessive-compulsive disorder, though here there is more evidence that the beneficial effects of selective serotonin reuptake inhibitors are independent of their antidepressant action..$^{910}$

Some reports have claimed that fluvoxamine and fluoxetine are more effective than other antidepressants in potentially suicidal patients. ${ }^{11-13}$ In one of the studies, however, the difference between the effects of the selective uptake inhibitor and the control drug was not significant, ${ }^{11}$ while in all of them reliance was placed on "suicide items" in rating scales for depression. These are not accurate measures of the severity of genuine suicidal intent or predictors of subsequent suicidal behaviour.

The part played by 5-hydroxytryptamine in a wide range of 